\title{
A clinically significant right renal mass identified as an incidental finding on endoscopic ultrasound examination
}

The incidence of detection of an asymptomatic malignant disease or of another clinically important condition by endoscopic ultrasound (EUS) performed for another indication is unknown and is probably much higher than is generally recognized. Renal incidentalomas identified at EUS, particularly of the right kidney, remain poorly characterized.

A 57-year-old woman with a history of acute pancreatitis presented for further evaluation by EUS. Radial EUS revealed a normal gallbladder, bile duct, pancreatic parenchyma, and pancreatic duct, and there was no evidence of regional adenopathy. An incidental lesion on the apex of the right kidney and several small renal cysts were identified, however ( $\bullet$ Fig. 1 , - Video 1). A linear echo endoscope examination confirmed the findings ( $\bullet$ Fig. 2), although fine-needle aspiration was not performed. These EUS findings were confirmed by a subsequent renal ultrasound examination, which revealed a $1.5-\mathrm{cm}$, echo-poor, solid-looking mass, also visualized on computed tomographic urography ( Fig. 3). The patient had no history of flank discomfort, hematuria, urinary tract infection, or kidney stones. An open partial right nephrectomy was performed, when a well-circumscribed, 2-cm lesion was enucleated without complications. Histologically, this was a grade 2 T1a clear cell renal cell carcinoma, without evidence of tumor necrosis.

The widespread use of advanced imaging techniques has led to increased identification of incidental renal cell carcinomas. Solid renal masses are present in $0.32 \%$ of the population [1]. The pre-test probability of finding clinically relevant extracolonic disease in average-risk, asymptomatic adults at computed tomographic colonoscopy is reported to be $4 \%-86 \%$ [2]. EUS-guided fine-needle aspiration diag-

\section{Video 1}

Radial endoscopic ultrasonography revealed an $11 \times 5-\mathrm{mm}$, echo-poor lesion on the surface of the right kidney.

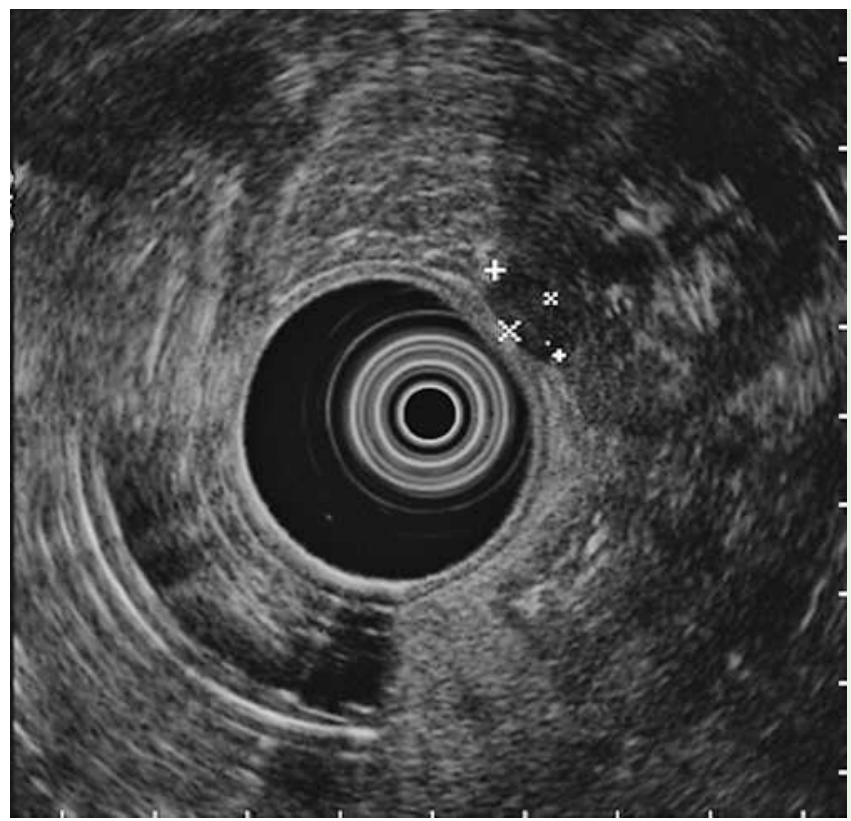

Fig. 1 Radial endoscopic ultrasound (EUS) view of an echo-poor lesion, $11 \times 5 \mathrm{~mm}$ in size, on the surface of the right kidney.

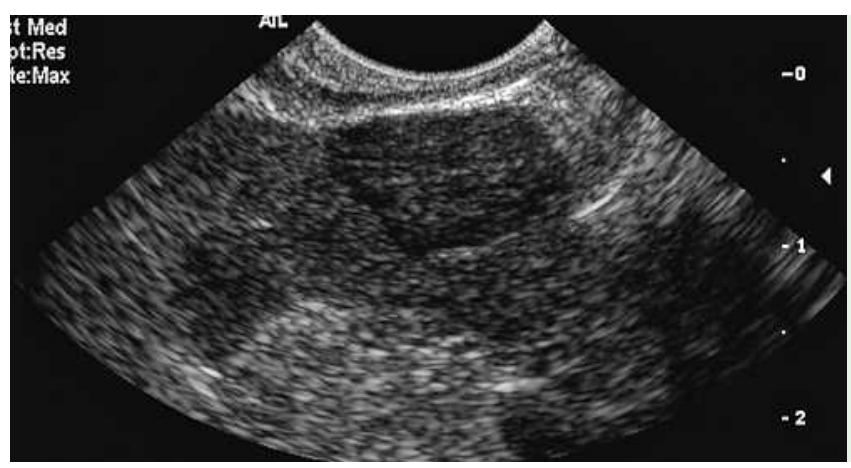

Fig. 2 Linear EUS view of the echo-poor exophytic renal lesion first identified on radial EUS.

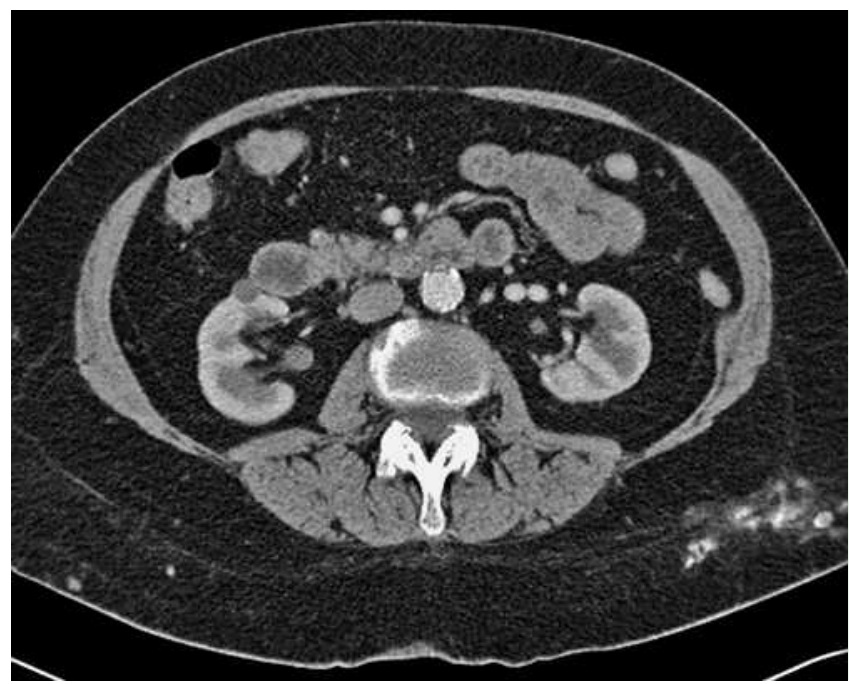

Fig. 3 A computed tomographic view of a mass on the anterior kidney, an appearance in keeping with either a small renal cell carcinoma or a benign oncocytoma. 1.5-cm, solid-looking aspect of the right 
nosis of primary renal cell carcinoma and of metastatic renal cell carcinoma to the mediastinum and pancreas has been reported [3-5]. This case illustrates a clinically significant finding in an area not commonly visualized by EUS.

Endoscopy_UCTN_Code_CCL_1AF_2AG_3AB

\section{F. C. Gleeson, G. I. Papachristou,}

M. J. Levy

Division of Gastroenterology and Hepatology, Mayo Clinic Foundation, Rochester, Minnesota, USA

\section{References}

1 Malaeb BS, Martin DJ, Littooy FN et al. The utility of screening renal ultrasonography: identifying renal cell carcinoma in an elderly asymptomatic population. BJU Int 2005 95: 977-981

2 Pickhardt PJ, Choi JR, Hwang I et al. CT virtual colonoscopy to screen for colorectal neoplasia in asymptomatic adults. N Engl J Med 2003; 349: 2189-2198

3 Farrell JJ, Brugge WR. EUS-guided fine-needle aspiration of a renal mass: an alternative method for diagnosis of malignancy. Gastrointest Endosc 2002; 56: 450-452

4 Fritscher-Ravens A, Sriram PV, Topalidis T et al. Endoscopic ultrasonography-guided fine-needle cytodiagnosis of mediastinal metastases from renal cell cancer. Endoscopy $2000 ; 32: 531-535$

5 Bechade D, Palazzo L, Fabre M, Algayres JP. EUS-guided FNA of pancreatic metastasis from renal cell carcinoma. Gastrointest Endosc 2003; 58: 784-788
Bibliography

DOI 10.1055/s-2007-966853

Endoscopy 2008; 40: E1 -E2

(c) Georg Thieme Verlag KG Stuttgart · New York . ISSN 0013-726X

\section{Corresponding author}

\section{J. Levy, MD}

Division of Gastroenterology and Hepatology Mayo Clinic College of Medicine 200 First Street SW, Charlton 8

Rochester

Minnesota 55905

USA

Fax: +1-507-266-3939

levy.michael@mayo.edu 